\title{
Urgences
}

\section{mation qui n'en...}

\section{Johanne Côté}

Numéro 15, octobre 1986

Épigraphiques

URI : https://id.erudit.org/iderudit/025280ar

DOI : https://doi.org/10.7202/025280ar

Aller au sommaire du numéro

Éditeur(s)

Urgences

ISSN

0226-9554 (imprimé)

1927-3924 (numérique)

Découvrir la revue

Citer ce document

Côté, J. (1986). mation qui n'en... Urgences, (15), 11-11.

https://doi.org/10.7202/025280ar

Ce document est protégé par la loi sur le droit d'auteur. L'utilisation des services d'Érudit (y compris la reproduction) est assujettie à sa politique d'utilisation que vous pouvez consulter en ligne.

https://apropos.erudit.org/fr/usagers/politique-dutilisation/
Cet article est diffusé et préservé par Érudit.

Érudit est un consortium interuniversitaire sans but lucratif composé de l’Université de Montréal, l'Université Laval et l'Université du Québec à Montréal. Il a pour mission la promotion et la valorisation de la recherche. https://www.erudit.org/fr/ 


\section{Johanne Côté}

Si la déclamation est déjà un abus de la narration au théâtre, le chant, qui est un abus de la déclamation n'est donc, comme on voit, que l'abus de l'abus.

Pierre Augustin Caron de Beaumarchais: Le barbier de Séville

mation qui n'en finissait plus. Elle se rappelait, mesure après mesure, mot après mot, syllabe après syllabe, monème après monème, soupir après soupir, et caetera, et caetera, et caetera, le temps où elle figurait en tête de ligne de la célèbre chorale pastorale de sa paroisse, l'Ode Dieux, qui s'exécutait tous les premiers dimanches du mois de vingt heures trente à vingt-deux heures, et où elle occupait la place centrale, donnant aux quarante-neuf autres choristes le sempiternel mouvement métronomique en usage sur scène autant que dans la salle; il lui revenait alors à la gorge le goût acide des comprimés de GRAVOL, préservatif inhérent à ce loisir indiscutablement promu à une carrière éternelle, mais, aussi loin que pouvait régresser sa mémoire, elle avait conservé ce rythme de va-et-vient contracté depuis sa tendre enfance et qui ne lui faisait jamais défaut, même dans sa démarche caméléonesque: d'un fémur à l'autre; un devant l'autre derrière, d'un humérus à l'autre; un devant l'autre derrière, d'un occiput à l'autre; d'un océan à l'autre; et caetera, et caetera, et caetera, et elle se rappelait même encore l'année 1979, année bénie où elle accédait enfin, après tant et tant d'inlassables exercices vocaux et de cruauté mentale à force de chorales, à l'opéra français qui ne chante qu'en espagnol et en latin, où elle ne savait absolument pas ce qu'elle racontait mais où elle se rappelait cette maxime d'un Américain très connu mais dont elle avait complètement oublié le nom et qui disait: "un opéra se termine quand la grosse chanteuse se tait", et elle se répétait alors jours après jour, heure après heure, minute après minute, seconde après seconde, et caetera, et caetera, et caetera: "non, je ne me tairai pas", puis, épuisée par cette tirade qui s'étirait en longueur, elle respira profondément, revendiqua le centre de la scène, songea à son amant assis devant, adopta une pose baroque, sursauta au son du tambour, ferma les yeux, les ouvrit momentanément histoire de voir où se cachait le caméraman, et s'engagea, un octave plus haut cette fois et avec encore plus de coeur, dans une décla- 